\title{
ORLANDO FIGES: \\ NATAŠIN PLES: KULTURNA ZGODOVINA RUSIJE
}

Ljubliana: Modrijan, Studia humanitatis, 2007, 602 strani.

Prevedel: Matej Venier.

Mitološko mišljenje je zagotovo globoko vtkano v sleherni družbeni milje in prav Zahod je ustvaril enega najbolj trdovratnih mitov o Vzhodu - eksotično Rusijo. Koncepcijo "pristno ruskega« je na Zahod sicer res izvozil sam Ruski balet, vendar si velja zadevo pobliže pogledati in odkriti, kako je tudi ta kulturni glasnik deloval v službi procesov, ki so potekali v matični domovini. Mitske predstave in podobe vedno odražajo potrebo po iskanju odgovorov na temeljna človeška vprašanja, ki jih logični diskurz v določenem trenutku ni zmožen obvladovati. Pogosto, tako kot v primeru Rusije zadnjih dveh stoletij, služi mitološko za konstrukcijo sveta, ki v iskanju lastne identitete - predvsem skozi izjemen naboj, ki ga umetniška energija ponuja $\mathrm{v}$ tej prostrani deželi - pojasnjuje idejo o narodu in tako ustvarja rusko narodno zavest. Da bi si dinamiko tega barvitega sveta ruske kulturne zgodovine ogledali natančneje, se bomo odzvali povabilu na ples zgodovinarja Orlanda Figesa in prelistali njegovo delo z naslovom Natašin ples.

Kje iskati pravo Rusijo in kaj pomeni biti Rus? Figesova knjiga o ruski kulturni zgodovini se poda $\mathrm{v}$ vrtoglavo privlačen ples koketiranja $z$ Evropo na eni strani in Azijo na drugi, s kultom Sankt Peterburga in Moskve, z mogočnim ruskim carstvom in preprosto blatno vasjo neznansko velikega podeželja. Je to pot iskanja »ruske duše«? Ruski pregovor pravi: »Sankt Peterburg je naša glava, Moskva pa je naše srce.« In Rusija 18. stoletja se je delila na dva svetova - del družbe je zaznamovala evropska kultura višjih slojev in je pravzaprav vzniknil kot legenda iz močvare ob izlivu reke Neve v Baltsko morje (Peter Veliki naj bi na tem mestu razjahal konja in navkljub neusmiljeni naravi $\mathrm{z}$ besedami $» \mathrm{Tu}$ bo mesto! «zasnoval čarobno rusko pravljico z imenom Sankt Peterburg), 
preostali živelj pa je pripadal kulturi ruskega tlačanstva. Ta dva "načina biti« sta se prvič srečala v vojni leta 1812 (kot odgovor na Napoleonov vdor v Rusijo), ko sta se bok ob boku borila kmet in plemič, slednji pa je spoznal, da je edino pristno domoljubje tlačanov tisto, kar bo rešilo očetnjavo. Ti svobodomiselni plemiči so se uprli za "narod« in »ljudsko stvar« 14. decembra $1825 \mathrm{v}$ uporu, pozneje poznanem pod imenom »vstaja dekabristov«. Prelom je porodil »otroke leta 1812 «, ki so si prizadevali očistiti Rusijo vsega tujega - predvsem pravil in togega reda, ki so ga v preteklosti uvozili v vnemi, da bi se približali omikanemu Zaho$\mathrm{du}, \mathrm{v}$ resnici pa je vse skupaj družbo le utesnjevalo, da ni izoblikovala svoje narodne zavesti, utemeljene na lastnih načelih. $\mathrm{V}$ hrepenenju po "pristno ruskem « se je porodilo kmečko vprašanje. Zanj je bilo potrebno živeti v preprostosti in dihati s podeželjem (mnogi plemiči so dejansko zavezali cule in se odselili na deželo med revne kmete). Da bi se plemstvo lahko približalo ljudem do take mere, da bi jih izobrazilo, se je angažirala ustvarjalnost - vsaka od vej umetnosti je poskušala ujeti »narodni $\operatorname{slog}$ «, da bi ga, podobno kot so v preteklosti ljudstvu nedvoumno "spregovorile« ikone, prav razumeli. Kmalu pa je isti kulturni prostor, ki je sproduciral mit o dobrem, pristnem ruskem kmetu, slednjega odčaral. Kmečko vprašanje je bilo resda v središču pozornosti, vendar je bila vsaka njegova razrešitev mit.

Kolesje se je odtlej večkrat zavrtelo, tovrstni napori oblikovanja idej pa so odigrali svojo vlogo pri usmerjanju ruske politike in izdelavi samopodobe ruskega človeka; skoznje se je začela zrcaliti osebna in narodova identiteta, ki se je nenazadnje manifestirala pri preprostih, vsakdanjih opravilih kot je izbira hrane in obleke. Zanimivo je, da ideje - pa čeprav organsko povezane $\mathrm{z}$ narodno zavestjo, ki so jo vseskozi ovijali v mit - pojasnjujejo moč, s katero se je oblikovala ruska dejanskost. Prav velike osebnosti ruske kulturne tradicije (tu najdemo bleščeča imena književnikov, slikarjev, glasbenikov, gledališčnikov in filmarjev kot Karamzim, Puškin, Glinka, Gogolj, Tolstoj, Turgenjev, Dostojevski, Čehov, Repin, Čajkovski, Rimski-Korsakov, Djagilev, Stravinski, Prokofjev, Šostakovič, Chagall, Kandinski, Mandelštam, Ahmatova, Nabokov, Pasternak, Mejerhold, Ejzenštejn, Tarkovski in mnoge druge) so imele privilegij, da se je po njihovih žilah pretakala dediščina, ki je združevala tako »rusko« kot evropsko lice. 
Kako je bila ruska avtentičnost raznobarvna, nam pripoveduje paleta primerov, ki jih je v svoji knjigi predstavil Figes. Med njimi je zagotovo posebej pomenljiv naslednji: leta 1891 je bila izdelana prva matrjoška, nezamenljiva in vsem poznana ruska lutka, ki ima $v$ notranjščini vedno manjše, ravno tako votle dvojnike. Ti so vsak s svojo figuraliko predstavljali drugačen vidik kmečkega življenja. Pozneje izjemno priljubljena stara igračka pa ni bila nič drugega kot ruski posnetek japonske votle lutke; bila je torej daleč od tega, da bi izhajala iz avtentično ruskega ljudskega kulturnega izročila (str. 269). Nič manj dražestna ni v iskanju pristnosti zbirka ruskih osebnosti in radovedno plezanje po njihovih genealoških drevesih. Napoleon je nekoč rekel: "Popraskaj Rusa in našel boš Tatara." (str. 358). Odlični pričevalec ruskega sveta Aleksander Hercen je na primer dejal, da je Nikolaj I. »Džingiskan $z$ brzojavom «, o Stalinu pa so v duhu iste tradicije govorili, da je $» D z ̌ i n-$ giskan s telefonom « (str. 364). Med zahodnjaki dobro poznana figura Aleksandra Sergejeviča Puškina ob razkritju, da je ta literarni klasik po materini strani izhajal iz Afrike (bil je pravnuk Abrahama Hanibala - Etiopca, ki ga je ruski veleposlanik v Istanbulu kupil in podaril
Petru Velikemu), doživi še eno metamorfozo, ki pritiče skrivnostnemu izvoru ljudi z vzhoda (str. 363). Podobno se radovedni bralec lahko seznani, kako so se na obrazu Vladimirja Iljiča Uljanova kratko Lenina izrisovale jasne mongolske poteze (str. 370). Takšnih primerov je v Figesovi knjigi obilo.

Ko govorimo o Rusiji in "njeni duši«, se moramo zavedati še enega zelo pomembnega dejstva, in sicer da je biti »Rus« v prvi vrsti pomenilo tudi biti "pravoslaven« (str. 300). V 18. in 19. stoletju je bilo celotno rusko življenje prežeto $\mathrm{z}$ verskimi obredi, prav pravoslavni obredi pa so bili jedro ruske vere in narodne zavesti. Pri tem so odločilno vlogo odigrali poganski običaji, ki so vplivali na obredje in okrasje (zanimivost $\mathrm{v}$ zvezi z rdečo barvo, ki je imela posebno magično moč in je krasila pasove ter ogrinjala pri verskih obredih, je tudi ta, da je beseda rdeč (krasnyj) v ruščini povezana $\mathrm{z}$ besedo lep ( $\mathrm{kra}$ sivyj), od tu pa do poimenovanja Rdečega trga v Moskvi je le korak) (str. 318). "Ruska duša " pa ni predstavljala le poenotenje enega naroda, temveč je kot zgled skušala še enkrat v zgodovini postaviti Vzhod za učitelja Zahoda. Nikolaj Vasiljevič Gogolj je bil na primer prepričan, da je prav ta duša rešiteljica Zahoda in ji 
je to poslanstvo podelil $\mathrm{v}$ romanu Mrtve duše (Andrej Tarkovski je pozneje oživil ta mit $\mathrm{v}$ znamenju nasprotovanja sovjetskemu režimu in veri v odtujeni razumski materializem, ko je v svojem filmu Nostalgija iz leta 1983 v zadnji prizor postavil porušeno italijansko katedralo $s$ preprosto rusko kmečko hišo $\mathrm{v}$ njeni notranjosti). Skratka, v iskanju »ruske duše« so se združile različne prakse čaščenja plemičev in kmetov, pod isto streho pa so se znašla tudi iskanja smisla kulturnikov in narodno zagretih domoljubnežev.

Preostaneta nam še zadnji dve poglavji knjige $\mathrm{z}$ naslovoma Rusija skozi sovjetsko lečo in Rusija zdoma. Avtor je sodobnemu obdobju namenil opazno drugačno perspektivo - zarisal ga je bolj kot niz strahot in bil pri tem manj analitičen. Zato naj na tem mestu tudi nam spregovori kar pesnik Osip Emiljevič Mandelštam, ki je v tridesetih letih izrekel naslednje: "Poezijo spoštujejo samo pri nas - zaradi nje ubijajo." (str. 470). Njegova namenoma zelo razumljiva in vsakomur pomensko dostopna pesem, ki jo je napisal novembra 1933 in na skrivaj prebral prijateljem (dogodku je sledila aretacija), priča o življenju pod Stalinovo jekleno roko (str. 471):

\author{
Zdaj živimo, ne čutimo tal pod nogami, \\ in besed ne razločimo na nekaj korakov, \\ kjer pa najdemo čas za pogovor, \\ se omenja gorjanec iz Kremlja. \\ Ima prste debele in mastne kot črve, \\ njegove besede so zveste kot krogle. \\ Smejijo se ščurkasti brki, \\ bleščijo golenice škornjev. \\ Okrog njega je sodrga tankovratnih vo- \\ diteljev - \\ rad se igra $z$ uslugami polljudi. \\ Ta mijavka, ta žvižga, ta joče - \\ a le on godrnja in vse zmerja. \\ Ukaz za ukazom kuje kot podkve - \\ zdaj v dimlje, pa v čelo, obrvi in oči. \\ Sama kazen ga je - in nebesa, \\ pa širok prsni koš Osetinca.
}

Podobno zapuščino o skoraj neizrekljivo grozljivih razmerah prinaša pesniški cikel Rekviem, s katerim je Ana Ahmatova postala glasnica svojega ljudstva (pesnica je čas neme groze - in praktično vse življenje - preživela v Sankt Peterburgu v Hiši na Fontanki). Prav srhljivo je brati njene besede, ko je drugo svetovno vojno označila za olajšanje $\mathrm{v}$ primerjavi s stanjem, ki je vladalo $\mathrm{v}$ letih ustrahovanja. Vsem grozodejstvom pa tudi po vojni ni bilo videti konca. Poleg režima, ki ni prizanašal nikomur, lahko v knjigi sledimo rekam emigrantov. Kot večni tujci na Zahodu so najpogosteje zelo osamljeni in nerazumljeni hrepeneli po »svoji Rusiji«. Toda - kakšna je bila spet ta Rusija? 
Knjiga Orlanda Figesa je sprehod skozi ogledala predstav, navad, idej - skozi srž kulturne zgodovine Rusije. Pa naj Rusija živi v prizoru iz Tolstojevega romana Vojna in mir, kjer se plemkinja Nataša prvič $\mathrm{v}$ življenju zavrti v "pristno ruskih" ritmih, čeprav jih ni nikoli poprej slišalo njeno uho, ali pa $\mathrm{v}$ bogatem izboru palete kulturnih dosežkov dveh stoletij ruske zgodovine - vse do časa, ko smo se tudi mi približali idejnemu svetu povojnega sovjetskega režima. Avtor je zagotovo hotel poudariti stališče, da čiste, nacionalne kulture ni, saj lahko obstajajo le njene mitske podobe. Hkrati pa se $\mathrm{v}$ bogati teksturi besedila ni polotil rušenja teh mitov, temveč jim je še enkrat naklonil moč, da so zažareli v svojih barvah in tako sami pojasnili silovitost, s katero so vpeli svoj angažma in (pre)oblikovali rusko narodno zavest. Slediti tem potem $\mathrm{z}$ Orlandom Figesom predstavlja pravi užitek.

Slovenski prevod Natašinega plesa je svetlobo ugledal jeseni 2007 štiri leta po izidu izvirnika, knjigo pa sta $\mathrm{z}$ roko $\mathrm{v}$ roki izdali založbi Modrijan in Studia humanitatis. Naj na tem mestu dodam še majceno opozorilo: v slovenski izdaji Natašinega plesa je znamenita Malevičeva slika Rdeča konjenica obrnjena v napačno smer - levo je desno in desno je levo. Delo sicer odlikuje odličen prevod Mateja Venierja, ki se je soočil z izredno privlačnim in bralcu prijaznim slogom Orlanda Figesa, nekaj pesmi pa je v slovenščini prvič dobilo svojo podobo pod peresom Milana Jesiha in Toneta Pavčka. V spremni besedi Igorja Grdine lahko izvemo več o avtorju knjige, hkrati pa razmislimo o nekaterih ključnih vprašanjih v zvezi s (kulturno) zgodovino, njenim razvojem, njenih zablodah in nenehnim (nujnim) iskanjem lastne poti na svoji raziskovalni poti. 